\title{
Prevalência de Dores Musculoesqueléticas em Trabalhadores Rurais: Uma Revisão
}

\section{de Literatura}

\author{
Prevalence of Musculoskeletal Pain in Rural Workers: A Review of the Literature \\ Prevalencia del Dolor Musculoesquelético en Trabajadores Rurales: Una Revisión de la Literatura
}

Recebido: 17/06/2021 | Revisado: 22/06/2021 | Aceito: 24/06/2021 | Publicado: 10/07/2021

Taís Regina Fiegenbaum

ORCID: https://orcid.org/0000-0002-0788-5900 Universidade do Vale do Taquari, Brasil

E-mail: taisfiegenbaum@gmail.com

Enzo Vinícius Souza Santana

ORCID: https://orcid.org/0000-0002-0977-8682

Universidade do Vale do Taquari, Brasil

E-mail: enzo.santana@ universo.univates.br

Claudete Rempel

ORCID: https://orcid.org/0000-0001-8573-0237 Universidade do Vale do Taquari, Brasil

E-mail: crempel@univates.br

Magali Teresinha Quevedo Grave

ORCID: https://orcid.org/0000-0001-7911-1018 Universidade do Vale do Taquari, Brasil E-mail:mgrave@univates.br

\begin{abstract}
Resumo
Introdução: Visando acompanhar as modificações que ocorrem no setor rural em decorrência do avanço tecnológico, se fazem necessárias adaptações ergonômicas e posturais nos locais de trabalho, interferindo diretamente sobre suas formas de trabalho e produção. Aliado a isso, os trabalhadores rurais enfrentam uma série de fatores de risco, que somados, predispõem estes trabalhadores ao desenvolvimento de Dores Musculoesqueléticas (DME). Objetivo: Analisar, bibliograficamente, as taxas de prevalência de DME em trabalhadores rurais. Materiais e métodos: Ao todo foram encontradas 831 produções científicas acerca da prevalência de DME em agricultores, nos últimos cinco anos. Após a exclusão de duplicatas e de produções que não possuíam relação com o tema proposto, foram analisadas 55 produções científicas, na íntegra, que se enquadraram nos critérios de inclusão, sendo que destas, 35 contribuíram para responder a questão norteadora da presente revisão. Quanto à prevalência de DME,os resultados demonstram que demonstram uma maior prevalência de DME na coluna vertebral, com maior incidência sobre a coluna lombar, sobre a coluna lombar, ombro e joelho dos trabalhadores rurais analisados. Conclusão: $\mathrm{O}$ estudo permitiu identificar um alto índice de prevalência de DME em trabalhadores rurais. Entretanto, não se pode afirmar que esta população é mais acometida por DME quando comparada com populações de outros setores de trabalho.
\end{abstract}

Palavra-chave: Fazendeiros; Dor musculoesquelética; Ergonomia; Saúde da população rural.

\begin{abstract}
Introduction: In order to accompany the changes that occur in the rural sector as a result of technological advances, ergonomic and postural adaptations are required in the workplaces, directly interfering with their forms of work and production. Objective: To analyze bibliographically the rates of prevalence of DME in rural workers. Materials and methods: In all, 831 scientific productions were found on the prevalence of DME in farmers in the last five years. After excluding duplicates and productions that weren't related to the proposed theme, 55 scientific productions in full that met the inclusion criteria were analyzed, of which 35 contributed to answer the guiding question of this review. As for the prevalence of DME, results were found that demonstrate a higher prevalence of DME in the spine, with a higher incidence on the lumbar spine, on the shoulder and on the knee in the analyzed rural workers. Conclusion: The study made it possible to identify a high prevalence of DME in rural workers. However, it cannot be said that this population is more affected by DME when compared to populations from other sectors of work.
\end{abstract}

Keywords: Farmers; Musculoskeletal pain; Ergonomics; Rural health.

\section{Resumen}

Introducción: con el objetivo de acompañar los cambios que ocurren en el sector rural como resultado de los avances tecnológicos, son necesarias adaptaciones ergonómicas y posturales en los locales de trabajo, interfiriendo directamente en sus formas de trabajo y producción. Aliado a esto, los trabajadores rurales enfrentan una serie de factores de riesgo, 
que en conjunto predisponen a estos trabajadores al desarrollo de dolor musculoesquelético (DME). Objetivo: Analizar bibliográficamente las tasas de prevalencia de DME en trabajadores rurales. Materiales y métodos: En total, se encontraron 831 producciones científicas sobre la prevalencia de DME en agricultores en los últimos cinco años. Después de la exclusión de duplicados y de producciones que no tuvieran relación con la temática propuesta, se analizaron 55 producciones científicas en su totalidad que cumplieron con los criterios de inclusión, y de estas, 35 contribuyeron a responder la pregunta orientadora de esta revisión. En cuanto a la prevalencia de DME, se encontraron resultados que demuestran una mayor prevalencia de DME en la columna vertebral, con una mayor incidencia en la columna lumbar, hombro y rodilla en los trabajadores rurales analizados. Conclusión: El estudio permitió identificar una alta tasa de prevalencia de DME en trabajadores rurales. Sin embargo, no se puede decir que esta población se vea más afectada por el DME en comparación con poblaciones de otros sectores laborales.

Palabras clave: Agricultores; Dolor musculoesquelético; Ergonomía; Salud de la población rural.

\section{Introdução}

O desenvolvimento da tecnologia vem trazendo grandes implicações no setor rural e urbano, fazendo com que se tenha a necessidade de adaptação por parte dos trabalhadores às mudanças físicas e ergonômicas encontradas nos locais de trabalho. Além dessas características, o trabalhador rural enfrenta uma série de desafios como a baixa remuneração, a falta de mão de obra, a realização de trabalho em múltiplos setores, a labuta com equipamentos pesados, a insatisfação com seu trabalho, a dificuldade de locomoção, a inserção precoce de crianças ao trabalho, a dificuldade de aposentadoria digna, dentre outros (Ulbricht, 2003).

O trabalho no meio rural difere-se do realizado no meio urbano, seja pela proximidade entre o local de trabalho e a sua moradia; seja pelo distanciamento entre o meio rural e o centro da cidade, local onde se localizam os serviços de saúde ou, ainda, pelo fato do trabalho rural ser, em geral, de grande exigência física e ter impactos substanciais nas queixas de dores das pessoas, principalmente quando idosas (Ulbricht, 2003; Silveira et al., 2008). Esses fatores, somados ao ritmo de trabalho intenso, a manipulação e o transporte de altas cargas, exposição a agentes químicos e parasitários, ao estresse decorrente da falta de socialização e da dificuldade em associar ao trabalho uma vida social ativa, manuseio errôneo e inadequado dos equipamentos de trabalho e acúmulo e sobrecarga de funções, fazem com que o agricultor fique propenso ao desenvolvimento de Dores Musculoesqueléticas (DME) resultantes da demanda física e mental imposta por suas atividades laborais (Da Silva et al., 2020). Dentre as causas mais comuns para o surgimento de DME, está a presença de Doenças Osteomusculares Relacionadas ao Trabalho (DORT), oriundas de atividades laborais extenuantes ou repetitivas (Biazus; Moretto; Pasqualotti, 2017).

De acordo com a Pesquisa Nacional de Saúde (PNS) realizada no ano de 2013 com a contribuição do Instituto Brasileiro de Geografia e Estatística (IBGE) e do Ministério da Saúde (MS), foram encontrados 3.568.095 indivíduos com diagnóstico de DORT em relação a uma amostra de 146,3 milhões de pessoas. Além disso, entre os anos de 2011 e 2013, os principais acidentes de trabalho que necessitaram de recursos financeiros da Previdência Social foram, primeiramente, os fatores externos e, posteriormente, as DORTs. Estas, caracterizadas por serem doenças de caráter multifatorial, podem ser consequência das atividades laborais realizadas de maneira extenuante, repetitiva ou com sobrecarga mecânica e física, podendo causar, em seus portadores, incapacidades físicas temporárias ou permanentes para a realização de seu trabalho ou até mesmo a morte.

O trabalhador rural é exposto diariamente a inúmeros fatores de risco para o desenvolvimento de DME e, por esta razão, acredita-se que há uma relação de proximidade entre ambos. Devido à baixa qualificação dos trabalhadores e à grande necessidade de acompanhar os anseios do comércio, os trabalhadores rurais realizam atividades prejudiciais à sua saúde, dentre as quais destacam-se o aumento das horas diárias de trabalho, o trabalho com equipamentos vibracionais ou pesados e a adoção de más posturas para o desenvolvimento de seu trabalho. Diante do exposto, o objetivo do presente estudo foi revisar, bibliograficamente, a prevalência de DME em trabalhadores rurais. 


\section{Metodologia}

O presente estudo compreendeu uma revisão de literatura (Estrela, 2018; Pereira et al., 2018), sendo a coleta de dados realizada por meio de uma busca de artigos científicos nas bases de dados Scopus, Pubmed, EBSCO, Periódicos da Capes e Scielo. A busca foi realizada entre os meses de março e junho de 2020, tendo como base a seguinte questão norteadora: "Qual a produção científica nacional e internacional acerca das prevalências de DME em trabalhadores rurais?".

Todos os artigos disponibilizados nas bases de dados foram analisados e tiveram seus títulos e resumos lidos, sendo selecionados para a leitura na íntegra aqueles que se enquadraram nos seguintes critérios de inclusão: (1) artigos científicos publicados entre os anos de 2015 e 2020, (2) desenhos metodológicos observacionais ou ensaios clínicos, (3) avaliação da presença de DME, (4) avaliação de agricultores, (5) artigos redigidos em português, espanhol ou inglês. Optou-se por este período para recorte temporal devido às exigências de periódicos atuais para a citação de artigos com até cinco anos de publicação. Para a realização da busca foram utilizados os termos "Farmers" e "Musculoskeletal Diseases", bem como seus operadores boleanos. A estratégia de busca utilizada no Pubmed pode ser observada na Tabela 1.

Tabela 1 - Estratégias de busca no Pubmed.

\begin{tabular}{|c|c|}
\hline \#3 & Search (\#1 AND \#2) \\
\hline \#\# & $\begin{array}{l}\text { Search (Musculoskeletal Diseases"[Mesh] OR "Musculoskeletal Disease” OR “Orthopedic Disorders" } \\
\text { OR “Orthopedic Disorder) }\end{array}$ \\
\hline $\begin{array}{l}\text { \#\# } \\
1\end{array}$ & $\begin{array}{l}\text { Search ("Farmers" OR "Farmer" OR "Farm Workers" OR "Farm Worker" OR "Worker, Farm" OR } \\
\text { "Workers, Farm" OR "Agricultural Workers" OR "Agricultural Worker" OR "Worker, } \\
\text { Agricultural”[Mesh] OR "Workers, Agricultural" OR "Farmworkers" OR "Farmworker" OR } \\
\text { "Ranchers" OR "Rancher") }\end{array}$ \\
\hline
\end{tabular}

Fonte: Autores.

\section{Resultados}

A busca inicial resultou em um total de 831 artigos, sendo 46 artigos na base de dados Pubmed, 160 no Periódico da Capes, 3 no Scielo, 602 no Scopus e 20 no EBSCO. Desse total, 55 eram duplicatas, restando 776 artigos para a leitura de títulos e resumos, sendo posteriormente descartados os artigos de revisão, de reflexão e artigos que não tinham relação com o tema proposto. Nessa fase, preencheram os critérios de elegibilidade 55 artigos, que posteriormente tiveram seu conteúdo lido na íntegra. Após a leitura, apenas 35 preencheram todos os critérios de elegibilidade e foram incluídos na presente revisão. A Figura 1 apresenta o fluxograma das etapas de inclusão dos estudos na revisão de literatura. 
Figura 1: Fluxograma das etapas de inclusão dos estudos da revisão de literatura.

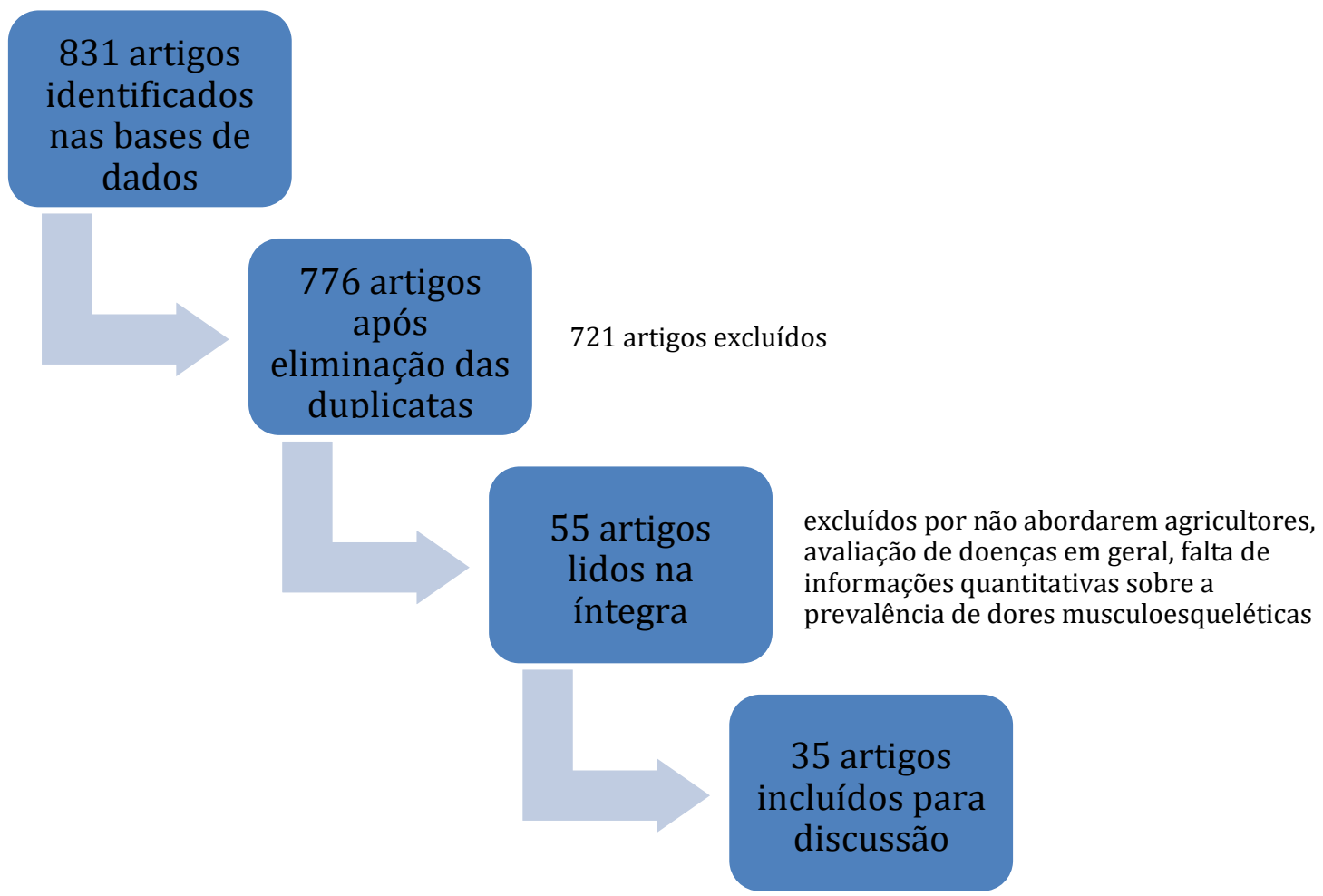

Fonte: produzida pelos autores.

A análise dos artigos consistiu em algumas etapas pré-estabelecidas, sendo elas: leitura e criação de quadro sinóptico contendo informações de ano de publicação, periódico, autor(es), título e procedência do artigo; e avaliação de conteúdo do artigo, onde foram explorados os conteúdos, os tratamentos dos resultados obtidos pelos autores e a interpretação dos dados. Visando respeitar os autores e as questões éticas envolvidas em um estudo de revisão, os nomes dos autores foram citados.

Entraram para a revisão de literatura 35 artigos que buscaram responder à questão norteadora e atenderam aos critérios de inclusão. Primeiramente, no quadro 1 são apresentados os artigos inseridos na revisão de literatura, bem como os resultados encontrados que buscam auxiliar na produção de conhecimento em relação à prevalência de DME em agricultores.

Quadro 1 - Apresentação e caracterização dos artigos que preencheram todos os critérios de elegibilidade.

\begin{tabular}{|c|c|c|c|c|c|}
\hline Ano & Autores & Título & Sujeitos & Metodologia & Resultados \\
\hline 2019 & $\begin{array}{l}\text { Maradei F; } \\
\text { Jaimes CPA; } \\
\text { Sarmiento } \\
\text { SJS. }\end{array}$ & $\begin{array}{l}\text { Síntomas } \\
\text { musculoesquelétic } \\
\text { os en las } \\
\text { actividades de } \\
\text { cosecha de mora } \\
\text { de Castilla de } \\
\text { Piedecuesta, } \\
\text { Colombia }\end{array}$ & $\begin{array}{l}72 \text { agricultores, } \\
\text { sendo } 40 \\
\text { homens e a } \\
\text { média de idade } \\
\text { de 39,3 anos }\end{array}$ & $\begin{array}{l}\text { Nordic } \\
\text { Musculoskeletal } \\
\text { Questionnaire (NMQ) }\end{array}$ & $\begin{array}{l}81,9 \% \text { dos sujeitos relataram possuir algum } \\
\text { tipo de dor, sendo as prevalências: Lombar: } \\
63,9 \% \text {; Pescoço: } 47,2 \% \text {; Ombro: } 49,3 \% \text {; } \\
\text { Mãos: } 45,7 \% \text {. }\end{array}$ \\
\hline 2017 & $\begin{array}{l}\text { Biazus M; } \\
\text { Moretto CF; } \\
\text { Pasqualotti A. }\end{array}$ & $\begin{array}{lr}\text { Relação entre } & \text { ejas de dor } \\
\text { queixas } & \text { musculoesquelétic } \\
\text { a e processo de } & \\
\text { trabalho } & \text { na } \\
\text { agricultura } & \\
\text { familiar } & \end{array}$ & $\begin{array}{l}150 \text { agricultores, } \\
\text { sendo } \quad 76 \\
\text { homens com } \\
\text { média de idade } \\
\text { de } 48,37 \text { anos }\end{array}$ & $\begin{array}{l}\text { Questionário Nórdico } \\
\text { de Sintomas } \\
\text { Osteomusculares } \\
\text { (NMQ) adaptado; e } \\
\text { questionário } \\
\text { sociodemográfico e a }\end{array}$ & $\begin{array}{l}80,7 \% \text { dos sujeitos relataram possuir algum } \\
\text { tipo de dor, sendo as prevalências: Lombar: } \\
71,3 \% \text {; Ombro: } 37,3 \% \text {; Punhos e mãos: } \\
\text { 28,7\%; Joelhos: } 26,7 \% \text {; Pescoço: } 24,7 \% \text {; } \\
\text { Quadril e coxas: } 14,0 \% \text {; Cotovelos: } 14,0 \% \text {; } \\
\text { Tornozelos e pés: } 8,7 \% \text {; Cervical: } 3,3 \% \text {. }\end{array}$ \\
\hline
\end{tabular}




\begin{tabular}{|c|c|c|c|c|c|}
\hline & & & & $\begin{array}{l}\text { escala analógica visual } \\
\text { (EVA). }\end{array}$ & \\
\hline 2019 & $\begin{array}{l}\text { Kim M; Yoo } \\
\text { JI; Kim MJ; } \\
\text { Na JB; Lee SI; } \\
\text { Park KS. }\end{array}$ & $\begin{array}{l}\text { Prevalence of } \\
\text { Upper Extremity } \\
\text { Musculoskeletal } \\
\text { Diseases and } \\
\text { Disability among } \\
\text { Fruit Tree Farmers } \\
\text { in Korea: Cross- } \\
\text { Sectional Study }\end{array}$ & $\begin{array}{l}460 \text { agricultores, } \\
\text { sendo } 223 \\
\text { homens e a } \\
\text { média de idade } \\
\text { de } 59,67 \text { anos }\end{array}$ & $\begin{array}{l}\text { Questionário } \\
\text { Disabilities of the } \\
\text { Arm, Shoulder, and } \\
\text { Hand (DASH) }\end{array}$ & $\begin{array}{l}89,6 \% \text { dos sujeitos tinham alguma dor } \\
\text { musculoesquelética em membros superiores, } \\
\text { sendo elas: } \\
\text { Ruptura do manguito rotador: } 60,4 \% \text {; } \\
\text { Cotovelo de golfe: } 20,9 \% \text {; Cotovelo de } \\
\text { tenista: } 40,9 \% \text {; Osteoartrite de mão: } 58 \% \text {. }\end{array}$ \\
\hline 2017 & $\begin{array}{l}\text { Thetkathuek } \\
\text { A; Meepradit } \\
\text { P; } \quad \text { Sa- } \\
\text { ngiamsak T. }\end{array}$ & $\begin{array}{l}\text { A Cross-sectional } \\
\text { Study of } \\
\text { Musculoskeletal } \\
\text { Symptoms and } \\
\text { Risk Factors in } \\
\text { Cambodian Fruit } \\
\text { Farm Workers in } \\
\text { Eastern Region, } \\
\text { Thailand }\end{array}$ & $\begin{array}{l}861 \text { agricultores, } \\
\text { sendo } 501 \\
\text { homens e a } \\
\text { média de idade } \\
\text { de } 30,7 \text { anos }\end{array}$ & $\begin{array}{l}\text { Rapid Upper Limb } \\
\text { Assessment (RULA) }\end{array}$ & $\begin{array}{l}\text { Lombar: } 41,3 \% \text {; Torácica: } 28,2 \% \text {; Cervical: } \\
23,9 \% \text {; Joelho: } 13,5 \% \text {; Tornozelo: } 11,1 \% \text {; } \\
\text { Quadril e coxa: } 17,1 \% \text {; Ombro: } 21,6 \% \text {; } \\
\text { Cotovelo: } 4,4 \% \text {; Punho e mão: } 11,7 \% \text {. }\end{array}$ \\
\hline 2018 & $\begin{array}{l}\text { Jain R; } \\
\text { Meenaa ML; } \\
\text { Dangayacha } \\
\text { GS; } \\
\text { Bhardwaja } \\
\text { AK. }\end{array}$ & $\begin{array}{l}\text { Association of risk } \\
\text { factors with } \\
\text { musculoskeletal } \\
\text { disorders in } \\
\text { manual working } \\
\text { farmers }\end{array}$ & $\begin{array}{l}138 \text { agricultores, } \\
\text { sendo } 114 \\
\text { homens com } \\
\text { média de idade } \\
\text { de } 35 \text { anos }\end{array}$ & $\begin{array}{l}\text { Rapid Upper Limb } \\
\text { Assessment (RULA) }\end{array}$ & $\begin{array}{l}76,4 \% \text { dos sujeitos tinham alguma dor } \\
\text { musculoesquelética em membros superiores } \\
\text { e tronco, sendo elas: Lombar: } 71,4 \% \text {; Dedos: } \\
\text { 62,1\%; Ombros: } 56,4 \% \text {; Mãos/pulsos: } 55 \% \text {; } \\
\text { Cotovelos/antebraços: 46,4; Pescoço: } \\
\text { 41,4\%; Torácica: } 36,4 \% \text {. }\end{array}$ \\
\hline 2018 & $\begin{array}{l}\text { Jain R; Meena } \\
\text { ML; Bhardwaj } \\
\text { AK. }\end{array}$ & $\begin{array}{l}\text { Risk Factors for } \\
\text { Musculoskeletal in } \\
\text { Disorders } \\
\text { Manual } \\
\text { Harvesting } \\
\text { Farmers of } \\
\text { Rajasthan }\end{array}$ & $\begin{array}{l}140 \text { agricultores, } \\
\text { sendo } \quad 114 \\
\text { homens com } \\
\text { média de idade } \\
\text { de } 38,36 \text { anos }\end{array}$ & $\begin{array}{l}\text { Rapid Upper Limb } \\
\text { Assessment (RULA) }\end{array}$ & $\begin{array}{l}77,9 \% \text { dos sujeitos tinham alguma dor } \\
\text { musculoesquelética, sendo elas: Lombar: } \\
74 \% \text {; Dedos: } 64,2 \% \text {; Ombros: } 57,1 \% \text {; } \\
\text { Punhos e mãos: 55,7\%; Cotovelos e } \\
\text { antebraços: 47,1\%; Pescoço: } 42,1 \% \text {; } \\
\text { Torácica: } 37,1 \% \text {. }\end{array}$ \\
\hline 2018 & $\begin{array}{lr}\text { Ya'acob } & \mathrm{NA} ; \\
\text { Abidin } & \mathrm{EZ} ; \\
\text { Rasdi } & \mathrm{I} ; \\
\text { Rahman } & \text { AA; } \\
\text { Ismail S. } & \end{array}$ & $\begin{array}{l}\text { Reducing work- } \\
\text { related } \\
\text { musculoskeletal } \\
\text { symptoms through } \\
\text { implementation of } \\
\text { Kiken Yochi } \\
\text { training } \\
\text { intervention } \\
\text { approach }\end{array}$ & $\begin{array}{l}45 \text { agricultores } \\
\text { homens com } \\
\text { média de idade } \\
\text { de } 33,69 \text { anos }\end{array}$ & $\begin{array}{l}\text { Nordic } \\
\text { Musculoskeletal } \\
\text { Questionnaire (NMQ) } \\
\text { e Rapid Upper Limb } \\
\text { Assessment (RULA) }\end{array}$ & $\begin{array}{l}\text { Cervical: 4,5\%; Ombros: } 28,9 \% \text {; Cotovelo: } \\
\text { 15,6\%; Mãos/braços: 4,5\%; Torácica: 8,9\%; } \\
\text { Lombar: } 46,7 \% \text {; Coxa: 8,9\%; Joelho: } 46,7 \% \text {; } \\
\text { Tornozelo/pé: } 24,5 \% \text {. }\end{array}$ \\
\hline 2016 & $\begin{array}{lr}\text { Swanberg J; } \\
\text { Clouser JM; } \\
\text { Gan } \quad \text { W; } \\
\text { Flunker JC; } \\
\text { Westneat S; } \\
\text { Browning SR }\end{array}$ & $\begin{array}{l}\text { Poor safety } \\
\text { climate, long work } \\
\text { hours, and } \\
\text { musculoskeletal } \\
\text { discomfort among } \\
\text { Latino horse farm } \\
\text { workers }\end{array}$ & $\begin{array}{l}225 \text { agricultores, } \\
\text { sendo } 193 \\
\text { homens com } \\
\text { média de idade } \\
\text { de } 35 \text { anos }\end{array}$ & $\begin{array}{ll}\text { Guia Nacional de } \\
\text { Entrevistas de } \\
\text { Desconforto Corporal }\end{array}$ & $\begin{array}{l}85 \% \text { dos sujeitos tinham alguma dor } \\
\text { musculoesquelética, sendo elas: Pescoço e } \\
\text { costas: } 66 \% \text {; Membros superiores: } 68 \% \text {; } \\
\text { Membros inferiores: } 60 \% \text {. }\end{array}$ \\
\hline 2016 & Kang MY et al & $\begin{array}{l}\text { Musculoskeletal } \\
\text { Disorders and } \\
\text { Agricultural Risk } \\
\text { Factors Among } \\
\text { Korean Farmers }\end{array}$ & $\begin{array}{l}15.980 \\
\text { agricultores, } \\
\text { sendo } 8138 \\
\text { homens com } \\
\text { média de idade } \\
\text { de } 66,7 \text { anos }\end{array}$ & $\begin{array}{l}\text { Questionário } \\
\text { demográfico } \\
\text { profissional }\end{array}$ & 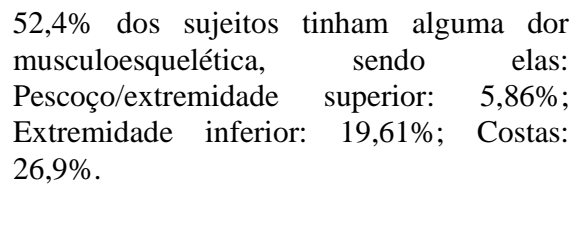 \\
\hline 2016 & $\begin{array}{l}\text { Douphrate DI; } \\
\text { Nonnenmann } \\
\text { MW; }\end{array}$ & $\begin{array}{l}\text { Work-Related } \\
\text { Musculoskeletal } \\
\text { Symptoms and Job }\end{array}$ & $\begin{array}{l}450 \text { agricultores, } \\
\text { sendo } \quad 400 \\
\text { homens } \quad \text { com }\end{array}$ & $\begin{array}{l}\text { Nordic } \\
\text { Musculoskeletal } \\
\text { Questionnaire (NMQ) }\end{array}$ & $\begin{array}{l}\text { Extremidade superior: acima de } \\
60 \% \text {; Extremidade inferior: quase } 60 \% \text {, em }\end{array}$ \\
\hline
\end{tabular}




\begin{tabular}{|c|c|c|c|c|c|}
\hline & $\begin{array}{l}\text { Hagevoort R; } \\
\text { Porras DGR. }\end{array}$ & $\begin{array}{l}\text { Factors among } \\
\text { Large-Herd Dairy } \\
\text { Milkers }\end{array}$ & $\begin{array}{l}\text { média de idade } \\
\text { de } 30 \text { anos }\end{array}$ & & $\begin{array}{l}\text { média; Pescoço e parte superior das costas: } \\
\text { cerca de } 50 \% \text {; Lombar: acima de } 30 \% \text {. }\end{array}$ \\
\hline 2016 & $\begin{array}{lr}\text { Kearney } & \text { GD; } \\
\text { Allen } & \text { DL; } \\
\text { Balanay JAG, } \\
\text { Barry P. }\end{array}$ & $\begin{array}{l}\text { A Descriptive } \\
\text { Study of Body } \\
\text { Pain and Work- } \\
\text { related } \\
\text { Musculoskeletal } \\
\text { Disorders among } \\
\text { Latino } \\
\text { Farmworkers } \\
\text { Working on Sweet } \\
\text { Potato Farms in } \\
\text { Eastern N.C. }\end{array}$ & $\begin{array}{l}120 \text { agricultores, } \\
\text { sendo } 115 \\
\text { homens com } \\
\text { média de idade } \\
\text { de } 32,5 \text { anos }\end{array}$ & $\begin{array}{l}\text { Nordic } \\
\text { Musculoskeletal } \\
\text { Questionnaire (NMQ) }\end{array}$ & $\begin{array}{l}79,2 \% \text { dos sujeitos tinham alguma dor } \\
\text { musculoesquelética, sendo elas: Lombar: } \\
\text { 45\%; Sacral: } 19,2 \% \text {; Torácica: } 10 \% \text {; Ombro: } \\
30,8 \% \text {; Joelho: } 26,7 \% \text {. }\end{array}$ \\
\hline 2015 & $\begin{array}{l}\text { Tonelli S; } \\
\text { Culp K; } \\
\text { Donham KJ. }\end{array}$ & $\begin{array}{l}\text { Prevalence of } \\
\text { Musculoskeletal } \\
\text { Symptoms and } \\
\text { Predictors of } \\
\text { Seeking } \\
\text { Healthcare among } \\
\text { Iowa Farmers }\end{array}$ & $\begin{array}{l}412 \text { agricultores, } \\
\text { sendo } \quad 374 \\
\text { homens com } \\
\text { média de idade } \\
\text { de } 56,08 \text { anos }\end{array}$ & $\begin{array}{l}\text { Triagem clínica de } \\
\text { bem-estar e saúde } \\
\text { ocupacional }\end{array}$ & $\begin{array}{l}\text { Cervical: 50,97\%; Ombro: } 18 \% \text {; Cotovelo: } \\
\text { 25,72\%; Punho: 39,10\%; Torácica: 38,9\%; } \\
\text { Lombar: 70,9\%; Quadril: 37,1\%; Joelho: } \\
\text { 49,3\%; Pé: } 42 \% \text {. }\end{array}$ \\
\hline 2015 & $\begin{array}{lr}\text { Tribble } & \text { AG; } \\
\text { Summers } & \text { P; } \\
\text { Chen } & H ; \\
\text { Quandt } & \text { SA; } \\
\text { Arcury TA. }\end{array}$ & $\begin{array}{l}\text { Musculoskeletal } \\
\text { Pain, Depression, } \\
\text { and Stress among } \\
\text { Latino Manual } \\
\text { Laborers in North } \\
\text { Carolina }\end{array}$ & $\begin{array}{l}111 \text { agricultores } \\
\text { e } 78 \text { não } \\
\text { agricultores }\end{array}$ & $\begin{array}{l}\text { Questionário contendo } \\
\text { informações sobre } \\
\text { presença de dor em } 11 \\
\text { locais do corpo }\end{array}$ & $\begin{array}{l}\text { Pescoço e nos ombros: } 7,3 \% \text { dos } \\
\text { trabalhadores rurais contra } 17,1 \% \text { dos não } \\
\text { trabalhadores rurais, respectivamente; Mãos } \\
\text { e nos pulsos: } 9,2 \% \text { vs. } 15,7 \% \text {; Costas: } 15,5 \% \\
\text { vs } 22,1 \% \text {; Parte superior ou inferior da } \\
\text { perna: } 11,7 \% \text { vs. } 15,7 \% \text {. }\end{array}$ \\
\hline 2016 & Jo $\mathrm{H}$ et al & $\begin{array}{l}\text { Farmers' Cohort } \\
\text { for Agricultural } \\
\text { Work-Related } \\
\text { Musculoskeletal } \\
\text { Disorders } \\
\text { (FARM) Study: } \\
\text { Study Design, } \\
\text { Methods, and } \\
\text { Baseline } \\
\text { Characteristics of } \\
\text { Enrolled Subjects }\end{array}$ & $\begin{array}{l}\text { - } 1013 \\
\text { agricultores, } \\
\text { sendo } 519 \\
\text { homens com } \\
\text { média de idade } \\
\text { de } 57,2 \text { anos }\end{array}$ & $\begin{array}{l}\text { Questionário } \\
\text { demográfico e } \\
\text { profissional e Índice } \\
\text { de Incapacidade } \\
\text { Oswestry }\end{array}$ & $\begin{array}{l}91,3 \% \text { dos sujeitos tiveram alguma dor } \\
\text { musculoesquelética, sendo elas: Lombar: } \\
\text { 63,8\%; Pernas / pés: } 43,3 \% \text {; Ombro: } 42,9 \% \text {; } \\
\text { Punho / mãos / dedo: 26,6\%; Braço / } \\
\text { cotovelo: } 25,3 \% \text {; Pescoço: } 21,8 \% \text {. }\end{array}$ \\
\hline 2015 & $\begin{array}{l}\text { Taylor-Gjevre } \\
\text { RM; Trask C; } \\
\text { King N; } \\
\text { Koehncke N. }\end{array}$ & $\begin{array}{l}\text { Prevalence and } \\
\text { Occupational } \\
\text { Impact of Arthritis } \\
\text { in Saskatchewan } \\
\text { Farmers }\end{array}$ & $\begin{array}{l}-2.473 \\
\text { participantes, } \\
\text { sendo } 328 \text { com } \\
\text { diagnóstico de } \\
\text { artrite }\end{array}$ & $\begin{array}{l}\text { Nordic } \\
\text { Musculoskeletal } \\
\text { Questionnaire (NMQ) } \\
\text { a avaliação de } \\
\text { atividades de risco }\end{array}$ & $\begin{array}{l}96,9 \% \text { dos avaliados com diagnóstico de } \\
\text { artrite tiveram DME, enquanto somente } \\
81,3 \% \text { dos avaliados sem diagnóstico de } \\
\text { artrite tiveram DME, respectivamente. } \\
\text { Mais especificamente, os indivíduos com } \\
\text { diagnóstico de artrite e os sem diagnóstico, } \\
\text { respectivamente, apresentaram maiores } \\
\text { DME em: } \\
\text { Cervical: } 48,6 \% \text { e } 38,7 \% \text {, respectivamente; } \\
\text { Ombros: } 58,4 \% \text { e } 42,4 \% \text {; Cotovelos: } 18,7 \% \\
\text { e } 15 \% \text {; Mãos: } 46,2 \% \text { e } 26,1 \% \text {; Torácica: } \\
24,5 \% \text { e } 20,2 \% \text {; Lombar: } 68,5 \% \text { e } 56,5 \% \text {; } \\
\text { Quadril: } 46,8 \% \text { e } 28,4 \% \text {; Joelho: } 63,3 \% \text { e } \\
33,1 \% \text {; Tornozelos: } 38,2 \% \text { e } 81,3 \% \text {. }\end{array}$ \\
\hline 2015 & Das B. & $\begin{array}{l}\text { Gender } \\
\text { differences in } \\
\text { prevalence of } \\
\text { musculoskeletal } \\
\text { disorders among } \\
\text { the rice farmers of } \\
\text { West Bengal, } \\
\text { India }\end{array}$ & $\begin{array}{l}220 \text { agricultores, } \\
\text { sendo } 110 \\
\text { homens com } \\
\text { média de idade } \\
\text { de } 35,2 \text { anos } \\
\text { para homens e } \\
4,3 \text { anos para } \\
\text { mulheres }\end{array}$ & $\begin{array}{l}\text { Questionário nórdico } \\
\text { modificado }\end{array}$ & $\begin{array}{l}90 \% \text { dos homens e } 98 \% \text { das mulheres } \\
\text { tiveram DME, sendo elas: Pescoço: } 52,7 \% \text {; } \\
\text { Ombro: } 60,9 \% \text {; Cotovelo: } 33,2 \% \text {; Punho: } \\
\text { 40\%; Mãos: 53,6\%; Torácica: 23,2\%; } \\
\text { Lombar: } 89,5 \% \text {; Joelho: } 80,9 \% \text {; Tornozelo: } \\
\text { 27,3\%; Pés: } 29,1 \% \text {. }\end{array}$ \\
\hline
\end{tabular}




\begin{tabular}{|c|c|c|c|c|c|}
\hline 2015 & $\begin{array}{l}\text { Kolstrup CL; } \\
\text { Jakob M. }\end{array}$ & $\begin{array}{l}\text { Epidemiology of } \\
\text { Musculoskeletal } \\
\text { Symptoms among } \\
\text { Milkers and Dairy } \\
\text { Farm } \\
\text { Characteristics in } \\
\text { Sweden and } \\
\text { Germany }\end{array}$ & $\begin{array}{l}92 \text { suecos e } 115 \\
\text { alemães, sendo a } \\
\text { idade média } \\
\text { entre } 40 \text { e } 42\end{array}$ & $\begin{array}{l}\text { Nordic } \\
\text { Musculoskeletal } \\
\text { Questionnaire }\end{array}$ & $\begin{array}{l}84 \% \text { dos suecos e } 85 \% \text { dos alemães tiveram } \\
\text { DME, sendo elas de suecos e alemães } \\
\text { respectivamente: Lombar: } 49 \% \text { e } 61 \% \text {; } \\
\text { Ombro: } 47 \% \text { e } 52 \% \text {; Pescoço: } 38 \% \text { e } 53 \% \text {; } \\
\text { Mãos / pulsos: } 32 \% \text { e } 42 \% \text {; Joelhos: } 24 \% \text { e } \\
\text { 36\%; Torácica: } 19 \% \text { e } 26 \% \text {; Cotovelos: } 17 \% \\
\text { e } 23 \% \text {; Pés: } 16 \% \text { e } 28 \% \text {; Quadril: } 11 \% \text { e } \\
27 \% \text {. }\end{array}$ \\
\hline 2015 & $\begin{array}{lr}\text { Baksh } & \text { KS; } \\
\text { Ganpat } & \text { W; } \\
\text { Narine LK. }\end{array}$ & $\begin{array}{l}\text { Occupational } \\
\text { Health and Safety } \\
\text { Issues among } \\
\text { Vegetable Farmers } \\
\text { in Trinidad and the } \\
\text { Implications for } \\
\text { Extension }\end{array}$ & $\begin{array}{l}100 \text { agricultores, } \\
\text { sendo } \quad 82 \\
\text { homens com } \\
\text { idades entre } \\
62 \mathrm{e} \\
60 \text { anos }\end{array}$ & $\begin{array}{l}\text { Questionário } \\
\text { demográfico } \\
\text { profissional } \\
\text { perguntas } \\
\text { direcionadas } \\
\text { prevalência de lesões }\end{array}$ & $\begin{array}{l}\text { 61\% dos sujeitos tiveram DME, sendo elas: } \\
\text { Lombar: 55\%; Torácica: } 26 \% \text {; Ombro: } 16 \% \text {; } \\
\text { Pescoço: } 15 \% \text {; Tornozelo/pé: } 7 \% \text {; Coxa / } \\
\text { joelho / pernas: } 6 \% \text {; Mão / punho / cotovelo } \\
\text { / antebraço: } 4 \% \text {. }\end{array}$ \\
\hline 2015 & $\begin{array}{lr}\text { McMillan } & \text { M; } \\
\text { Trask } & \mathrm{C} ; \\
\text { Dosman } & \mathrm{J} ; \\
\text { Hagel } & \mathrm{L} ; \\
\text { Pickett W. } & \end{array}$ & $\begin{array}{l}\text { Prevalence of } \\
\text { Musculoskeletal } \\
\text { Disorders Among } \\
\text { Saskatchewan } \\
\text { Farmers }\end{array}$ & $\begin{array}{l}-2595 \\
\text { agricultores, } \\
\text { sendo } 1549 \\
\text { homens com } \\
\text { média de idade } \\
\text { de 54,4 anos }\end{array}$ & $\begin{array}{l}\text { Nordic } \\
\text { Musculoskeletal } \\
\text { Questionnaire }\end{array}$ & $\begin{array}{l}85,4 \% \text { dos sujeitos tiveram DME, sendo } \\
\text { elas: Lombar: 57,7\%; Ombro: } 44 \% \text {; } \\
\text { Pescoço:, } 39,6 \% \text {. }\end{array}$ \\
\hline 2016 & Pinzke S. & $\begin{array}{l}\text { Comparison of } \\
\text { Working } \\
\text { Conditions and } \\
\text { Prevalence of } \\
\text { Musculoskeletal } \\
\text { Symptoms among } \\
\text { Dairy Farmers in } \\
\text { Southern Sweden } \\
\text { over a 25-Year } \\
\text { Period }\end{array}$ & $\begin{array}{l}- \\
\text { agricultores, } \\
\text { sendo } 186 \\
\text { homens }\end{array}$ & $\begin{array}{l}\text { Nordic } \\
\text { Musculoskeletal } \\
\text { Questionnaire }\end{array}$ & $\begin{array}{l}\text { Cervical: } 28,3 \% \text {; Ombro: } 44,5 \% \text {; Cotovelo: } \\
\text { 15,8\%; Punho / mão: 23,5\%; Torácica: } \\
\text { 11,7\%; Lombar: 52,6\%; Quadril: 25,9\%; } \\
\text { Joelhos: } 34,4 \% \text {; Pé: } 16,2 \% \text {. }\end{array}$ \\
\hline 2018 & $\begin{array}{lr}\text { Patil } & \text { SA; } \\
\text { Kadam } & \text { YR; } \\
\text { Mane } & \text { AS; } \\
\text { Gore } & \text { AD; } \\
\text { Dhumale } & \text { GB. }\end{array}$ & $\begin{array}{l}\text { The Prevalence } \\
\text { and Health Impact } \\
\text { of } \\
\text { Musculoskeletal } \\
\text { Disorders among } \\
\text { Farmers }\end{array}$ & $\begin{array}{l}\text { - } 1150 \\
\text { agricultores, } \\
\text { sendo } 711 \\
\text { homens com } \\
\text { média de idade } \\
\text { de } 47 \text { anos }\end{array}$ & $\begin{array}{l}\text { Sistema de Análise de } \\
\text { Posturas de Trabalho } \\
\text { de Ovako (OWAS) }\end{array}$ & $\begin{array}{l}83,8 \% \text { dos sujeitos tiveram DME, sendo } \\
\text { elas: Joelhos: } 34 \% \text {; Lombar: } 33 \% \text {; Cervical: } \\
\text { 24,7\%; Torácica: } 24,5 \% \text {; Ombro: } 23,7 \% \text {; } \\
\text { Quadril: } 18,5 \% \text {; Pé: } 17, \% \text {; Mão: } 9,7 \% \text {; } \\
\text { Cotovelo: } 6,2 \% \text {. }\end{array}$ \\
\hline 2015 & $\begin{array}{lr}\text { Mora } & \text { DC; } \\
\text { Miles } & \text { CM; } \\
\text { Arcury } & \text { TA. }\end{array}$ & $\begin{array}{l}\text { Prevalence of } \\
\text { musculoskeletal } \\
\text { disorders among } \\
\text { immigrant Latino } \\
\text { farmworkers and } \\
\text { non-farmworkers } \\
\text { in North Carolina }\end{array}$ & $\begin{array}{l}-\quad 272 \\
\text { trabalhadores, } \\
\text { sendo que destes } \\
157 \quad \text { eram } \\
\text { agricultores } \\
\text { (média de } 37 \\
\text { anos) e } 119 \\
\text { eram não } \\
\text { agricultores } \\
\text { (média de idade } \\
\text { de } 38 \text { anos) }\end{array}$ & $\begin{array}{l}\text { Exame físico realizado } \\
\text { por um médico }\end{array}$ & $\begin{array}{l}\text { - Para a amostra geral, as lesões } \\
\text { mais comuns foram: epicondilite }(20 \%) \text { e } \\
\text { síndrome do manguito rotador }(19 \%) \text {. Para } \\
\text { os agricultores foram: síndrome do manguito } \\
\text { rotador }(15,7 \%) \text {, dor lombar }(14 \%) \text { e } 9,2 \% \\
\text { possuíam patologias nos membros } \\
\text { inferiores. Para os trabalhadores não rurais } \\
\text { foram: a síndrome do manguito rotador } \\
(24 \%) \text {, epicondilite (22\%), dor lombar } \\
(21 \%) \text { e } 1,3 \% \text { possuíam patologias nos } \\
\text { membros inferiores. }\end{array}$ \\
\hline 2019 & $\begin{array}{lr}\text { Mokdad } & \text { M; } \\
\text { Bouhafs } & \text { M; } \\
\text { Lahcene } & \text { B; } \\
\text { Mokdad I. } & \end{array}$ & $\begin{array}{l}\text { Ergonomic } \\
\text { practices in Africa: } \\
\text { Date palm work in } \\
\text { Algeria as an } \\
\text { example }\end{array}$ & $\begin{array}{l}56 \text { agricultores } \\
\text { com média de } \\
\text { idade de } 42 \text { anos }\end{array}$ & $\begin{array}{l}\text { Nordic } \\
\text { Musculoskeletal } \\
\text { Questionnaire (NMQ) }\end{array}$ & $\begin{array}{l}\text { Prevalência de DME no último ano: Punhos } \\
\text { / mãos: } 100 \% \text {; Pés: } 94,5 \% \text {; Ombros: } 93 \% \text {; } \\
\text { Lombar: } 91 \% \text {; Joelhos: } 87,5 \% \text {; Torácica: } \\
\text { 69,5\%; Quadril: 52\%; Cervical: } 48 \% \text {; } \\
\text { Cotovelo: } 25 \% \text {. }\end{array}$ \\
\hline 2018 & \begin{tabular}{ll|} 
Nuraydın & A; \\
Bilek & $\ddot{O} ;$ \\
Yildız AN. &
\end{tabular} & $\begin{array}{l}\text { The Mersin } \\
\text { Greenhouse } \\
\text { Workers Study. } \\
\text { Surveillance of } \\
\text { Work-related }\end{array}$ & $\begin{array}{lr}- & 423 \\
\text { agricultores, } & \\
\text { sendo } & 247 \\
\text { homens } & \text { com }\end{array}$ & $\begin{array}{l}\text { Questionário } \\
\text { demográfico } \\
\text { profissional }\end{array}$ & $\begin{array}{l}\text { Lombar: } 72,8 \% \text {; Dores nas articulações: } \\
9,3 \% \text {; Distúrbio do disco intervertebral } \\
\text { torácico, toracolombar e lombossacro não } \\
\text { especificado: } 8,2 \% \text {; Mialgia: } 7,5 \% \text {; Mão / pé }\end{array}$ \\
\hline
\end{tabular}




\begin{tabular}{|c|c|c|c|c|c|}
\hline & & $\begin{array}{l}\text { Skin, Respiratory, } \\
\text { and } \\
\text { Musculoskeletal } \\
\text { Diseases }\end{array}$ & $\begin{array}{l}\text { média de idade } \\
\text { de } 41 \text { anos }\end{array}$ & & $\begin{array}{l}\text { / dedos da mão e dos pés: } 1,5 \% \text {; Desordens } \\
\text { do disco cervical: } 0,7 \% \text {; }\end{array}$ \\
\hline 2018 & $\begin{array}{l}\text { Houshyar E; } \\
\text { Kim IJ. }\end{array}$ & $\begin{array}{l}\text { Understanding } \\
\text { musculoskeletal } \\
\text { disorders among } \\
\text { Iranian apple } \\
\text { harvesting } \\
\text { laborers: } \\
\text { Ergonomic and } \\
\text { stopwatch time } \\
\text { studies }\end{array}$ & $\begin{array}{l}30 \text { agricultores } \\
\text { homens } \\
\text { divididos em } \\
\text { dois grupos: } \\
\text { jovem ( } 20 \text { a } 35 \\
\text { anos) e idoso ( } 36 \\
\text { a } 55 \text { anos) }\end{array}$ & $\begin{array}{l}\text { Nordic Standard } \\
\text { Questionnaire (NSQ), } \\
\text { sendo as avaliações } \\
\text { realizadas pré, } \\
\text { imediatamente após e } \\
\text { após } 12 \text { dias da } \\
\text { realização da colheita }\end{array}$ & $\begin{array}{l}\text { Prevalência aproximada antes da colheita } \\
\text { com 20-35 anos e } 36 \text { a } 55 \text { anos, } \\
\text { respectivamente: Lombar: } 58 \% \text { e } 52 \% \text {; } \\
\text { Joelho: } 53 \% \text { e } 53 \% \text {; Cervical: } 39 \% \text { e } 48 \% \text {; } \\
\text { Ombro } 35 \% \text { e } 42 \% \text {; Torácica: } 25 \% \text { e } 28 \% \text {; } \\
\text { Punho: } 16 \% \text { e } 18 \% \text {; Pés/tornozelos: } 14 \% \text { e } \\
\text { 15\%; Cotovelo: } 11 \% \text { e 14\%; Coxa: } 9 \% \text { e } \\
\text { 15\%. } \\
\text { Prevalência após colheita com } 20-35 \text { e } 36 \text { a } \\
56 \text { anos, respectivamente: Lombar: } 65 \text { e } \\
78 \% \text {; Joelho: } 63 \% \text { e } 71 \% \text {; Cervical: } 48 \% \text { e } \\
55 \% \text {; Ombro: } 41 \% \text { e } 49 \% \text {; Torácica } 32 \% \text { e } \\
36 \% \text {; Punho: } 15 \% \text { e } 19 \% \text {; Pés/tornozelos: } \\
15 \% \text { e } 14 \% \text {; Cotovelo: } 13 \% \text { e } 15 \% \text {; Coxa: } \\
10 \% \text { e } 13 \% \text {. } \\
\text { Prevalência após } 12 \text { dias de colheita, com } \\
\text { correção postural e repousos com } 20-35 \text { anos } \\
\text { e 36 a 55 anos: Joelho: } 45 \% \text { e } 44 \% \text {; Lombar: } \\
43 \% \text { e } 47 \% \text {; Cervical: } 29 \% \text { e } 32 \% \text {; Ombro: } \\
25 \% \text { e } 19 \% \text {; Torácica: } 18 \% \text { e } 18 \% \text {; } \\
\text { Pés/tornozelos: } 13 \% \text { e } 12 \% \text {; Cotovelo: } 9 \% \text { e } \\
9 \% \text {; Punho: } 8 \% \text { e } 15 \% \text {; Coxa: } 7 \% \text { e } 11 \% \text {. }\end{array}$ \\
\hline 2019 & Lee $\mathrm{H}$ et al. & $\begin{array}{l}\text { Difference in } \\
\text { health status of } \\
\text { Korean farmers } \\
\begin{array}{l}\text { according } \\
\text { gender }\end{array}\end{array}$ & $\begin{array}{l}434 \text { agricultores, } \\
\text { sendo } \quad 200 \\
\text { homens } \\
\text { média de } \text { idade } \\
\text { de } 62,7 \text { anos } \\
\text { para homens e } \\
\text { de } 60,9 \text { anos } \\
\text { para mulheres }\end{array}$ & $\begin{array}{l}\text { Questionário } \\
\text { demográfico e } \\
\text { profissional com } \\
\text { perguntas } \\
\text { direcionadas a saúde }\end{array}$ & $\begin{array}{l}67,2 \% \text { das mulheres e } 47 \% \text { dos homens } \\
\text { relataram DME, sendo elas: Cervical: } 9 \% \text {; } \\
\text { Ombro: 24,9\%; Braço: } 13,4 \% \text {; Coluna: } \\
\text { 32,9\%; Pernas: } 32,2 \% \text {; }\end{array}$ \\
\hline 2020 & $\begin{array}{l}\text { Dianat I; } \\
\text { Afshari D; } \\
\text { Sarmasti N; } \\
\text { Sangdeh MS; } \\
\text { Azaddel R. }\end{array}$ & $\begin{array}{l}\text { Work posture, } \\
\text { working } \\
\text { conditions and } \\
\text { musculoskeletal } \\
\text { outcomes in } \\
\text { agricultural } \\
\text { workers }\end{array}$ & $\begin{array}{lr}377 \text { agricultores, } \\
\text { sendo } \quad 149 \\
\text { homens } \quad \text { com } \\
\text { média de } \\
37,5 \text { idade }\end{array}$ & $\begin{array}{l}\text { Musculoskeletal } \\
\text { Nordic Questionnaire } \\
\text { (NMQ) }\end{array}$ & $\begin{array}{l}85,9 \% \text { dos sujeitos tiveram DME, sendo } \\
\text { elas: Lombar: } 75,1 \% \text {; Joelhos: } 62,1 \% \text {; } \\
\text { Torácica: } 61,5 \% \text {; Cervical: } 59,9 \% \text {; Ombro: } \\
\text { 43.8\%; Quadril: } 39,8 \% \text {; Mãos: } 36,1 \% \text {; Pés: } \\
\text { 27,3\%; Cotovelos: } 18 \% \text {. }\end{array}$ \\
\hline 2020 & $\begin{array}{lr}\text { Momeni } & \text { Z; } \\
\text { Choobineh } & \text { A; } \\
\text { Razeghi } & \text { M; } \\
\text { Ghaem r H; } & \text { Azadian F; } \\
\text { Daneshmandi } \\
\text { H. }\end{array}$ & $\begin{array}{l}\text { Work-related } \\
\text { Musculoskeletal } \\
\text { Symptoms among } \\
\text { Agricultural } \\
\text { Workers: A Cross- } \\
\text { sectional Study in } \\
\text { Iran }\end{array}$ & $\begin{array}{l}1501 \\
\text { agricultores, } \\
\text { sendo } 1336 \\
\text { homens com } \\
\text { média de idade } \\
41,39 \text { anos }\end{array}$ & $\begin{array}{l}\text { Musculoskeletal } \\
\text { Nordic Questionnaire } \\
\text { (NMQ) }\end{array}$ & $\begin{array}{l}\text { Lombar: 59,3\%; Joelhos: } 36,9 \% \text {; Torácica: } \\
\text { 36,6\%; Cervical: 36,5\%; Ombros: } 46,2 \% \text {; } \\
\text { Mãos: 34,77\%; Pés: 23,3\%; Cotovelos: } \\
\text { 21,98\%; Coxa: } 14,9 \% \text {. }\end{array}$ \\
\hline 2018 & $\begin{array}{l}\text { Lópes-Aragón } \\
\text { L; López-Líria } \\
\text { R; Callejón- } \\
\text { Ferre AJ; } \\
\text { Pérez-Alonso } \\
\text { J. }\end{array}$ & $\begin{array}{l}\text { Musculoskeletal } \\
\text { disorders of } \\
\text { agricultural } \\
\text { workers in the } \\
\text { greenhouses of } \\
\text { Almería } \\
\text { (Southeast Spain) }\end{array}$ & $\begin{array}{l}1002 \\
\text { agricultores, } \\
\text { sendo } 837 \\
\text { homens }\end{array}$ & $\begin{array}{l}\text { Musculoskeletal } \\
\text { Nordic Questionnaire } \\
\text { (NMQ) }\end{array}$ & $\begin{array}{l}\text { Cervical: } 35,3 \% \text {; Ombros: 16,7\%; } \\
\text { Cotovelo: 4,7\%; Punhos: } 8,3 \% \text {; Torácica: } \\
\text { 30,9\%; Lombar: } 67,2 \% \text {; Quadris ou coxas: } \\
\text { 20,75\%; Joelhos: } 29,3 \% \text {; Tornozelos / pé: } \\
\text { 11.9\%. }\end{array}$ \\
\hline 2018 & $\begin{array}{l}\text { Pal A; Dhara } \\
\text { PC. }\end{array}$ & $\begin{array}{l}\text { Work related } \\
\text { musculoskeletal } \\
\text { disorders and } \\
\text { postural stress of } \\
\text { the women }\end{array}$ & $\begin{array}{l}112 \text { agricultoras } \\
\text { mulheres com } \\
\text { média de idade } \\
\text { de } 34 \text { anos }\end{array}$ & $\begin{array}{l}\text { Questionário nórdico } \\
\text { modificado (NMQ) }\end{array}$ & $\begin{array}{l}\text { Lombar: } 91,96 \% \text {; Quadril: } 91,07 \% \text {; Punho: } \\
83,04 \% \text {; Torácica: } 81,25 \% \text {; Ombro: } \\
81,25 \% \text {; Pescoço: 73,21\%; Joelho: } \\
\text { 66,07\%; Cotovelo: } 62,5 \% \text {; Pé: } 47,32 \% .\end{array}$ \\
\hline
\end{tabular}




\begin{tabular}{|c|c|c|c|c|c|}
\hline & & $\begin{array}{l}\text { cultivators } \\
\text { engaged in } \\
\text { uprooting job of } \\
\text { rice cultivation }\end{array}$ & & & \\
\hline 2018 & $\begin{array}{l}\text { Moon DK et } \\
\text { al. }\end{array}$ & $\begin{array}{l}\text { Common Upper } \\
\text { Extremity } \\
\text { Disorders and } \\
\text { Function Affect } \\
\text { Upper Extremity- } \\
\text { Related Quality of } \\
\text { Life: A } \\
\text { Community- } \\
\text { Based Sample } \\
\text { from Rural Areas }\end{array}$ & 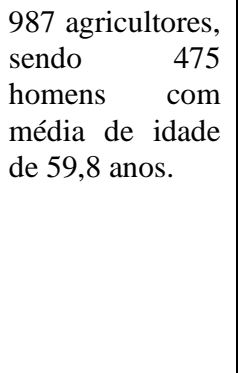 & $\begin{array}{l}\text { Questionário de Saúde } \\
\text { do Paciente-2 e } \\
\text { questionário DASH }\end{array}$ & $\begin{array}{l}\text { As prevalências de epicondilite, ruptura do } \\
\text { manguito rotador e Osteoartrite da mão em } \\
\text { todos os sujeitos foram de } 33,7 \%, 53,4 \% \text { e } \\
44,6 \% \text {, respectivamente. }\end{array}$ \\
\hline 2016 & $\begin{array}{l}\text { Stankevitz K; } \\
\text { Schoenfisch } \\
\text { A; Ostbye T. }\end{array}$ & $\begin{array}{l}\text { Prevalence and } \\
\text { risk factors of } \\
\text { musculoskeletal } \\
\text { disorders among } \\
\text { Sri Lankan rubber } \\
\text { tappers }\end{array}$ & $\begin{array}{l}300 \text { agricultores, } \\
\text { sendo } \quad 117 \\
\text { homens com } \\
\text { média de idade } \\
\text { de } 46,1 \text { anos }\end{array}$ & $\begin{array}{l}\text { Musculoskeletal } \\
\text { Nordic Questionnaire } \\
\text { (NMQ) e } r \text { Quick } \\
\text { Exposure }\end{array}$ & $\begin{array}{l}\text { 66\% dos sujeitos tiveram DME, sendo elas: } \\
\text { Costas: } 43 \% \text {; Ombros: } 28,3 \% \text {; pescoço: } \\
\text { 19,3\%; Mãos ou pulsos: } 16 \% \text {; Braços: } \\
15,3 \% \text {. }\end{array}$ \\
\hline 2016 & Min D et al. & $\begin{array}{l}\text { Prevalence and } \\
\text { Characteristics of } \\
\text { Musculoskeletal } \\
\text { Pain in Korean } \\
\text { Farmers }\end{array}$ & $\begin{array}{l}1.013 \\
\text { agricultores, } \\
\text { sendo } 479 \\
\text { homens r com } \\
\text { média de } \\
\text { de } 57,15 \text { anos }\end{array}$ & $\begin{array}{l}\text { Questionário padrão } \\
\text { para prevalência } \\
\text { autorreferida de } \\
\text { doenças } \\
\text { musculoesqueléticas e } \\
\text { características da dor, } \\
\text { desenvolvida pelo } \\
\text { KOSHA. }\end{array}$ & $\begin{array}{l}\text { As taxas de prevalência de um ano para } \\
\text { DME foram as seguintes: Lombar: } 63,8 \% \text {; } \\
\text { Perna / pé } 43,3 \% \text {; Ombro: } 42,9 \% \text {; Punho / } \\
\text { mãos / dedo: } 26,6 \% \text {; Braço / cotovelo: } \\
25,3 \% \text {; Pescoço: } 21,8 \% \text {. }\end{array}$ \\
\hline 2015 & $\begin{array}{lr}\text { Vasanth } & \mathrm{D} ; \\
\text { Ramesh } & \mathrm{N} ; \\
\text { Fathima } & \mathrm{FN} ; \\
\text { Fernandez } & \mathrm{R} ; \\
\text { Jennifer } & \mathrm{S} ; \\
\text { Joseph B. } & \end{array}$ & $\begin{array}{l}\text { Prevalence, } \\
\text { pattern, and } \\
\text { factors associated } \\
\text { with work-related } \\
\text { musculoskeletal } \\
\text { disorders among } \\
\text { pluckers in a tea } \\
\text { plantation in Tamil } \\
\text { Nadu, India }\end{array}$ & $\begin{array}{l}195 \text { agricultoras } \\
\text { mulheres com } \\
\text { média de idade } \\
\text { de } 45,6 \text { anos }\end{array}$ & $\begin{array}{l}\text { Musculoskeletal } \\
\text { Nordic Questionnaire } \\
\text { (NMQ) }\end{array}$ & $\begin{array}{l}\text { A prevalência de DME nos últimos } 12 \text { meses } \\
\text { e } 7 \text { dias foi de } 83,6 \% \text { e } 78,5 \% \text {, } \\
\text { respectivamente, sendo elas: } \\
\text { Em } 7 \text { dias: Lombar: } 52,8 \% \text {; Ombro: } 45,8 \% \text {; } \\
\text { Cervical: } 42 \% \text {; Joelho: } 38,2 \% \text {; Torácica: } \\
\text { 26,8\%; Cotovelo: } 24,5 \% \text {; Punho: } 23,6 \% \text {; } \\
\text { Tornozelo: } 6,6 \% \text {; Quadri:1 1,9\%. } \\
\text { Em } 12 \text { meses: Ombro: } 59 \% \text {; Lombar: } 58 \% \text {; } \\
\text { Cervical: } 49,1 \% \text {; Joelho: } 43,9 \% \text {; Cotovelo: } \\
\text { 41,5\%; Torácica: } 37,3 \% \text {; Punho: } 25,9 \% \text {; } \\
\text { Tornozelo: } 7,1 \% \text {; Quadril: } 3,3 \% \text {. }\end{array}$ \\
\hline 2015 & Ng YG et al. & $\begin{array}{l}\text { Risk factors of } \\
\text { musculoskeletal } \\
\text { disorders among } \\
\text { oil palm fruit } \\
\text { harvesters during } \\
\text { early harvesting } \\
\text { stage }\end{array}$ & $\begin{array}{l}446 \text { agricultores } \\
\text { do } \quad \text { sexo } \\
\text { masculino com } \\
\text { média de idade } \\
\text { de } 20 \text { anos }\end{array}$ & $\begin{array}{l}\text { Sistema de Avaliação } \\
\text { de Posturas de } \\
\text { Trabalho } \text { Ovako } \\
\text { (OWAS) r e } \\
\text { Questionário nórdico } \\
\text { modificado (NMQ) }\end{array}$ & $\begin{array}{l}\text { A prevalência de DME durante os } 12 \text { meses } \\
\text { anteriores foi de } 86 \% \text {, e durante os últimos } 7 \\
\text { dias foi de } 45 \% \text {. } \\
\text { Em } 7 \text { dias: Lombar: } 28 \% \text {; Joelho: } 15 \% \text {; } \\
\text { Ombro: } 13 \% \text {; Cervical: } 13 \% \text {; Torácica: } 8 \% \text {; } \\
\text { Mãos: } 6 \% \text {; Tornozelos: } 6 \% \text {; Cotovelos: } 7 \% \text {; } \\
\text { Coxas: } 6 \% \text {. } \\
\text { Em } 12 \text { meses: Lombar: } 58 \% \text {; Joelho: } 40 \% \text {; } \\
\text { Ombro: } 28 \% \text {; Cervical: } 26 \% \text {; Torácica: } \\
21 \% \text {; Mãos: } 19 \% \text {; Tornozelos: } 19 \% \text {; } \\
\text { Cotovelos: } 18 \% \text {; Coxas: } 16 \% \text {. }\end{array}$ \\
\hline
\end{tabular}

Fonte: Quadro sinóptico produzido pelos autores.

\section{Discussão}

Esta revisão de literatura buscou avaliar a prevalência de DME em trabalhadores agrícolas. Dos 35 artigos que se enquadraram nos critérios de inclusão, nove deles foram publicados no ano de 2015, nove em 2016, dois em 2017, nove em 2018, quatro em 2019 e dois em 2020. Com relação aos agricultores avaliados pelos estudos, um estudo buscou comparar a prevalência 
de DME em agricultores jovens e agricultores adultos, sendo o primeiro deles composto por sujeitos de 20 a 35 anos e o outro de 36 a 65 anos; um estudo buscou analisar a prevalência de DME em agricultores com diagnóstico de osteoartrite; outros dois estudos buscaram comparar a prevalência das dores em agricultores e não agricultores; ainda, um estudo buscou comparar alemães e suecos com relação a essa prevalência de dores; e, por fim, alguns estudos avaliaram somente os agricultores do sexo masculino (3) ou do sexo feminino (2).

Os métodos de avaliação da prevalência de DME variaram entre os estudos, mas alguns questionários foram bastante utilizados, sendo eles: Nordic Musculoskeletal Questionnaire (NMQ) (ou Questionário Nórdico de Sintomas Osteomusculares adaptado/modificado), citado por 15 estudos; questionário demográfico e profissional contendo informações sobre a presença de DME, estando presente em seis estudos, Rapid Upper Limb Assessment (RULA), utilizado por quatro estudos; e Ovako Working Posture Analysis System (OWAS), empregado em três estudos.

Com relação aos estudos que buscaram comparar agricultores e não agricultores, os resultados foram semelhantes entre ambos os estudos. O estudo de Tribble et al. (2015) demonstrou resultados que sugerem que agricultores possuem menor incidência de DME em pescoço, ombros, punhos, mãos, costas e pernas quando comparados com não agricultores. Entretanto, somente a divergência na prevalência de dor no pescoço e nos ombros foi significativa entre os grupos. Já com relação ao estudo de Mora et al. (2015), que buscou avaliar a incidência de doenças osteomusculares, foram encontrados resultados que demonstraram uma maior chance de desenvolvimento de epicondilite, síndrome do manguito rotador, dor lombar e dores nas pernas em trabalhadores não rurais quando comparados com trabalhadores rurais, com diferença significativa entre os grupos somente para a dor nos membros inferiores. Cabe ressaltar que ambos os estudos não padronizaram o grupo de trabalhadores não rurais, contemplando trabalhadores de diversas áreas e com divergentes tarefas, podendo ser elas com alta (construção civil, produção) ou baixa (desempregados, artistas) demanda física, o que acaba influenciando diretamente no resultado da comparação entre os grupos.

Nos estudos que buscaram avaliar os trabalhadores rurais do sexo feminino, foram encontrados resultados dissemelhantes entre ambos. No primeiro estudo, realizado por Pal e Dhara (2018), foram encontrados resultados elevados de frequência de DME entre os avaliados, sendo os valores superiores a 60\% para todos os locais avaliados, exceto para o pé, onde 47,32\% dos avaliados referiram a presença de dor. Em contrapartida, o estudo realizado por Vasanth et al. (2015) encontrou resultados de prevalência de DME menores quando comparados com o primeiro estudo, com apenas a categoria de dor em qualquer parte do corpo superando os $60 \%$ de prevalência. Os maiores índices de dor encontrados no primeiro estudo foram em lombar (91,96\%), quadril $(91,07 \%)$ e punho $(83,04 \%)$, enquanto que no segundo estudo foram em ombro (59\%), lombar (58\%) e cervical $(49,1 \%)$. Essas divergências de resultado podem estar relacionadas com a função que estas mulheres possuem na agricultura, sendo que no primeiro estudo elas são responsáveis pela cultivação de arroz, enquanto que no segundo estudo elas são arrancadoras de chá. A cultivação de arroz engloba diversos passos, com diferentes posturas e movimentos do corpo; ao contrário das arrancadoras de chá, que realizam somente a retirada do chá do solo, ficando sob a postura de flexão de tronco ou agachada, bem como, realizando movimentos repetitivos de membros superiores e tronco.

Com relação aos estudos que buscaram analisar somente os agricultores do sexo masculino, foram encontrados resultados análogos entre eles. O estudo de Ya'acob et al. (2018) buscou avaliar a influência de um treinamento baseado no Kiken Yochi entre homens trabalhadores de uma plantação na Malásia. Na pré intervenção foram encontrados resultados de prevalência que indicaram que as regiões lombar $(46,7 \%)$, joelho $(46,7 \%)$, ombro $(28,9 \%)$ e cotovelo $(15,8 \%)$ haviam sido as mais acometidas por dor. Semelhante a este, o estudo de Mokdad et al. (2019) encontrou resultados de prevalências superiores em punhos/mãos (100\%), pés (94,5\%), ombros (93\%), lombar (91\%) e joelhos (87,5\%); quando comparado ao primeiro estudo, o estudo de Mokdad et al. revela porcentagens de incidência duas vezes maiores em seus avaliados. $\mathrm{Ng}$ et al. (2015), avaliaram a prevalência de dores em agricultores nos sete dias que antecederam a avaliação e durante 12 meses que precederam a mesma. 
Em ambos os períodos analisados pelo estudo, os locais mais acometidos pelas DME foram semelhantes, sendo divergentes somente a porcentagem de incidência dessas dores, com resultados superiores durante o período de 12 meses quando comparado com o de sete dias. Os locais mais acometidos foram coluna lombar (58\% em 12 meses e $28 \%$ em sete dias, respetivamente), joelhos ( $40 \%$ e $15 \%)$, ombros ( $28 \%$ e $13 \%$ ) e cervical (26\% e 13\%). Nos três estudos foram encontrados resultados altos de prevalência de DME em locais como região lombar, joelhos e ombros. Entretanto, no estudo realizado por Mokdad et al. foram encontrados altos índices de DME em extremidades, tanto o complexo superior como inferior, o que não foi encontrado nos demais estudos. Esse resultado pode ser explicado pela função desses agricultores, já que os mesmos são trabalhadores de tamareira, local onde os mesmos realizam escaladas com o auxílio de uma corda, visando a retirada de suas frutas, sendo as extremidades indispensáveis para a sustentação desses trabalhadores.

O estudo de Houshyar e Kim (2018) buscou comparar trabalhadores rurais jovens com os adultos, sendo o primeiro grupo formado por indivíduos com idades entre 20 e 35 anos e o segundo com idades entre 36 e 65 anos. Ainda, o estudo buscou analisar a prevalência de DME antes e após a colheita realizada por estes trabalhadores. Os resultados encontrados demonstraram que antes da colheita havia maior prevalência de DME em indivíduos adultos quando comparado com os jovens, sendo a classificação de locais com maiores incidências consonante entre os grupos, com as maiores taxas encontradas nas regiões lombar, joelho, cervical e ombro, respectivamente. As percentagens de prevalência de dor musculoesquelética entre os grupos não foram largamente divergentes, sendo a maior diferença percentual encontrada para a variável lombar no pós colheita (13\%) e para a variável cervical no pré colheita, onde o grupo adulto apresentou maior prevalência de dor em ambas. Ainda, os índices de prevalência de DME após a colheita foram superiores quando comparados com o pré colheita em ambos os grupos e para todos os locais do corpo analisados, exceto para: o grupo jovem com relação à variável punho; e o grupo adulto com relação às variáveis pé/tornozelo e coxa. Esses resultados podem estar relacionados com uma maior demanda dessas articulações e musculaturas durante as demais tarefas realizadas por esses agricultores, como os afazeres domésticos e limpeza do local de trabalho, que são realizados em maior intensidade quando não há muito serviço na colheita.

O estudo de Taylor-Gjevre et al. (2015) buscou analisar a prevalência de DME em indivíduos com e sem o diagnóstico de doenças reumatológicas. Ao todo foram avaliados 2.473 agricultores, sendo que destes, 2.145 relataram não possuir diagnóstico de doenças reumatológicas e 328 relataram possuir artrite. Dentro do grupo de indivíduos com artrite, 101 foram diagnosticados com artrite reumatóide, 253 com osteoartrite e 26 com ambos os diagnósticos médicos. De todos os avaliados, 96,9\% dos indivíduos com artrite relataram possuir DME em qualquer parte do corpo, enquanto 81,3\% dos indivíduos sem diagnóstico também relataram DME. Quando analisados os dois grupos separadamente, o local mais acometido é a região lombar, com uma diferença de $12 \%$ entre os grupos e uma prevalência superior do grupo com artrite. Para as demais partes do corpo, há uma prevalência divergente de DME, sendo as mais prevalentes de um ou ambos os ombros (42,4\%), um ou ambos os joelhos $(58,4 \%)$ e pescoço $(48,6 \%)$ para o grupo com artrite, e de um ou ambos os ombros $(42,4 \%)$, pescoço $(38,7 \%)$ e um ou ambos os joelhos $(33,1 \%)$ para o grupo sem diagnóstico médico. De acordo com os resultados é possível verificar uma incidência superior no grupo de agricultores com diagnóstico de artrite quando comparado com o grupo sem diagnóstico médico. Além disso, o estudo identificou uma diminuição da participação em atividades físicas dos indivíduos que possuíam o diagnóstico de artrite quando em comparação com os que não possuíam diagnóstico de artrite, tanto em atividades físicas externas quanto as relacionadas com o trabalho na fazenda, fazendo com que esse diagnóstico de artrite influencie de forma negativa na qualidade de vida desses indivíduos.

Em relação ao quadro geral, dos 35 artigos analisados, 23 revelaram maiores índices de DME na região lombar. Ainda, altos índices também foram encontrados para outras regiões da coluna vertebral, como região torácica e pescoço. Essas altas prevalências podem estar relacionadas com uma demanda elevada de posicionamentos ergonômicos inadequados, principalmente com relação ao cultivo e à colheita, fases estas que necessitam de movimentos repetitivos de agachamento e 
torções da coluna vertebral. Outras áreas corporais com índices elevados de prevalência de dores foram o ombro e o joelho, articulações que são responsáveis pelo movimento das extremidades superiores e inferiores do corpo, respectivamente. Essas articulações, quando em altas demandas de movimentação, ou seja, movimentos repetitivos ou com alta carga, podem ser acometidas por desequilíbrios musculares e articulares, favorecendo o aparecimento das DME.

Embora a população analisada pelos estudos seja de agricultores, várias foram os tipos e formas de agricultura realizadas por eles, o que justifica a divergência de resultados tanto com relação ao índice de prevalência, quanto com relação aos locais do corpo mais afetados pelas DME. Dessa forma, indica-se a realização de novos estudos visando a análise da prevalência de DME em populações específicas de agricultores, com as mesmas tarefas e afazeres no local de trabalho.

\section{Conclusão}

Os resultados demonstram altas taxas de prevalência de DME em agricultores, sendo as maiores taxas encontradas em regiões da coluna vertebral, ombros e joelhos na população de agricultores estudada pelos artigos inseridos nesta revisão de literatura. Não se pode afirmar, através deste estudo, que os agricultores são mais propensos ao desenvolvimento de DME quando comparados com não agricultores, já que ambos os estudos que buscaram comparar estas duas populações não encontraram resultados superiores em agricultores.

Embora a população analisada pelos estudos seja de agricultores, várias foram os tipos e formas de agricultura realizadas por eles, o que justifica a divergência de resultados tanto com relação ao índice de prevalência, quanto com relação aos locais do corpo mais afetados pelas DME. Dessa forma, fazem-se necessários novos estudos que busquem avaliar a prevalência de DME em populações específicas de agricultores.

\section{Referências}

Aragón, L. L., Líria, R. L., Ferre, A. J. C., \& Alonso, J. P. (2018, novembro). Musculoskeletal disorders of agricultural workers in the greenhouses of Almería (Southeast Spain). Safety Science, 109, 219-235. 10.1016/j.ssci.2018.05.023.

Baksh, K. S., Ganpat, W. G., \& Narine, L. K. (2015, julho). Occupational health and safety issues among vegetable farmers in trinidad and the implications for extension. Journal of agricultural safety and health, 21(3), 159-171. 10.13031/jash.21.11060.

Biazus, M., Moretto, C. F., \& Pasqualotti, A. (2017, setembro) Relação entre queixas de dor musculoesquelética e processo de trabalho na agricultura familiar. Revista Dor, 18(3), 232-237. 10.5935/1806-0013.20170107.

Das, B. (2015, janeiro). Gender differences in prevalence of musculoskeletal disorders among the rice farmers of West Bengal, India. Work, 50(2), 229-240. $10.3233 /$ WOR-131694.

Da Silva, I. R., Xavier, D. M., Bonow, C. A., Camponogara, S., De Oliveira, A. M. N., da Silva, M. R. S., \& Cezar-Vaz, M. R. (2020). Percepção de agricultores de soja e arroz acerca dos riscos ocupacionais. Research, Society and Development, 9(11), 1-21. http://dx.doi.org/10.33448/rsd-v9i11.9543.

Dianat, I., Afshari, D., Sarmasti, N., Sangdeh, M. S., \& Azaddel, R. (2020, maio). Work posture, working conditions and musculoskeletal outcomes in agricultural workers. International Journal of Industrial Ergonomics, 77, 1-9. 10.1016/j.ergon.2020.102941.

Douphrate, D. I., Nonnenmann, M. W., Hagevoort, R., \& Porras, D. G. R. (2016, abril). Work-related musculoskeletal symptoms and job factors among largeherd dairy milkers. Journal of agromedicine, 21(3), 224-233. 10.1080/1059924X.2016.1179612.

Estrela, C. (2018). Metodologia Científica: Ciência, Ensino, Pesquisa. Editora Artes Médicas.

Houshyar, E., \& Kim, I. J. (2018, setembro). Understanding musculoskeletal disorders among Iranian apple harvesting laborers: Ergonomic and stop watch time studies. International Journal of Industrial Ergonomics, 67, 32-40. 10.1016/j.ergon.2018.04.007.

Instituto Brasileiro de Geografia e Estatística (IBGE). (2014). Pesquisa Nacional de Saúde 2013: percepção do estado de saúde, estilos de vida e doenças crônicas. https://biblioteca.ibge.gov.br/index.php/biblioteca-catalogo?id=291110\&view=detalhes.

Jain, R., Meena, M. L., \& Bhardwaj, A. K. (2018, maio). Risk factors for musculoskeletal disorders in manual harvesting farmers of Rajasthan. Industrial health, 56(3), 241-248. 10.2486/indhealth.2016-0084.

Jain, R., Meenaa, M. L., Dangayacha, G. S., \& Bhardwaja, A. K. (2018, janeiro). Association of risk factors with musculoskeletal disorders in manual-working farmers. Archives of environmental \& occupational health, 73(1), 19-28. 10.1080/19338244.2017.1289890. 
Jo, H., Baek, S., Park, H. W., Lee, S. A., Moon, J., Yang, J. E., \& Kang E. K. (2016, agosto). Farmers' cohort for agricultural work-related musculoskeletal disorders (farm) study: study design, methods, and baseline characteristics of enrolled subjects. Journal of epidemiology, 26(1), 50-56. 10.2188/jea.JE20140271.

Kang, M. Y., Lee, M. J., Chung, H., Shin, D. H., Youn, K. W., \& Im, S. H. (2016, abril). Musculoskeletal disorders and agricultural risk factors among Korean farmers. Journal of agromedicine, 21(4), 353-363. 10.1080/1059924X.2016.1178612.

Kearney, G. D., Allen, D. L., Balanay, J. A. G., \& Barry, P. (2016, abril). A descriptive study of body pain and work-related musculoskeletal disorders among Latino farmworkers working on sweet potato farms in eastern North Carolina. Journal of agromedicine, 21(3), 234-243. 10.1080/1059924X.2016.1178613.

Kim, M., Yoo, J. I., Kim, M. J., Na, J. B., Lee, S. I., \& Park, K. S. (2019, setembro). Prevalence of upper extremity musculoskeletal diseases and disability among fruit tree farmers in Korea: cross-sectional study. Yonsei medical journal, 60(9), 870-875. 10.3349/ymj.2019.60.9.870.

Kolstrup, C. L., \& Jakob, M. (2015, outubro). Epidemiology of musculoskeletal symptoms among milkers and dairy farm characteristics in Sweden and Germany. Journal of agromedicine, 21(1), 43-55. 10.1080/1059924X.2015.1106373.

Lee, H., Cho, S. Y., Kim J. S., Yoon, S. Y., Kim, B. I., An, J. M., \& Kim, K. B. (2019, março). Difference in health status of Korean farmers according to gender. Annals of occupational and environmental medicine, 31(1), 1-9. 10.1186/s40557-019-0287-7.

Maradei, F., Ardila-Jaimes, C. P., \& Sanabria-Sarmiento, S. J. (2019, fevereiro). Síntomas musculoesqueléticos en las actividades de cosecha de mora de castilla de piedecuesta, Colombia. Hacia promoción de la salud, 24(2), 91-106. 10.17151/hpsal.2019.24.2.8.

Mcmillan, M., Trask, C., Dosman, J., Hagel, L., \& Pickett, W. (2015, agosto). Prevalence of musculoskeletal disorders among Saskatchewan farmers. Journal of agromedicine, 20(3), 292-301. 10.1080/1059924X.2015.1042611.

Min, D., Baek, S., Park, H. W., Lee, S. A., Moon, J., Yang, J. E., \& Kang, E. K. (2016, janeiro). Prevalence and characteristics of musculoskeletal pain in Korean farmers. Annals of rehabilitation medicine, 40(1), 1-13. 0.5535/arm.2016.40.1.1.

Mokdad, M., Bouhafs, M., Lahcene, B., \& Mokdad, I. (2019, maio). Ergonomic practices in Africa: Date palm work in Algeria as an example. Work, 62(4), 657-665. 10.3233/WOR-192898.

Momeni, Z., Choobineh, A., Razeghi, M., Ghaem, H., Azadian, F., \& Daneshmandi, H. (2020, julho). Work-Related musculoskeletal symptoms among agricultural workers: a cross-sectional study in Iran. Journal of agromedicine, 25(3), 1-10. 10.1080/1059924X.2020.1713273.

Moon, D. K., Park, Y. J., Song, S. Y., Kim, M. J., Park, J. S., Nam, D. C., \& Park K. S. (2018, julho). Common upper extremity disorders and function affect upper extremity-related quality of life: a community-based sample from rural areas. Yonsei medical journal, 59(5), 669-676. 10.3349/ymj.2018.59.5.669.

Mora, D. C., Miles, C. M., \& Arcury, T. A. (2016, maio). Prevalence of musculoskeletal disorders among immigrant Latino farmworkers and non-farmworkers in North Carolina. Archives of environmental \& occupational health, 71(3), 136-143. 10.1080/19338244.2014.988676.

Ng, Y. G., Tamrin, S. B. M., Yusoff, I. S.M., Hashim, Z., Deros, B. M., Bakar, S. A., \& How, V. (2015). Risk factors of musculoskeletal disorders among oil palm fruit harvesters during early harvesting stage. Annals of Agricultural and Environmental Medicine, 22(2), 286-292. 10.5604/12321966.1152101.

Nuraydin, A., Bilek, Ö., \& Yıldız, A. N. (2018, agosto). The mersin greenhouse workers study. Surveillance of work-related skin, respiratory, and musculoskeletal diseases. Annals of global health, 84(3), 504-511. 10.29024/aogh.2315.

Pal, A., \& Dhara, P. C. (2018, dezembro). Work related musculoskeletal disorders and postural stress of the women cultivators engaged in uprooting job of rice cultivation. Indian journal of occupational and environmental medicine, 22(3), 163-169. 10.4103/ijoem.IJOEM_104_18.

Patil, S. A., Kadam, Y. R., Mane, A. S., Gore, A. D., \& Dhumale, G.B. (2018, janeiro). The prevalence and health impact of musculoskeletal disorders among farmers. Medical Journal of Dr. DY Patil Vidyapeeth, 11(6), 485-491. 10.4103/mjdrdypu.mjdrdypu_41_18.

Pereira, A. S., Shitsuka, D. M., Parreira, F. J., \& Shitsuka, R. (2018). Metodologia da pesquisa científica.[e-book]. Santa Maria. Ed UAB/NTE/UFSM. https://repositorio. ufsm. br/bitstream/handle/1/15824/Lic_Computacao_Metodologia-Pesquisa-Cientifica. pdf.

Pinzke, S. (2016, maio). Comparison of working conditions and prevalence of musculoskeletal symptoms among dairy farmers in southern Sweden over a 25year period. Frontiers in public health, 98(4), 1-12. 10.3389/fpubh.2016.00098.

Silveira, N. A., Nääs, I. A., Moura, D. J., Salgado, D. D., \& Silva R. B. T. R. (2008, dezembro). Labor Activities and Occupational Health in Brazilian Swine Production - A Case Study. Agricultural Engineering International: the CIGR Journal, X, 1-8. https://cigrjournal.org/index.php/Ejounral/article/view/1272.

Stankevitz, K., Schoenfisch, A., \& Ostbye, T. (2016, abril) Prevalence and risk factors of musculoskeletal disorders among Sri Lankan rubber tappers. International journal of occupational and environmental health, 22(2), 91-98. 10.1080/10773525.2016.1168073.

Swanberg, J., Clouser, J. M., Gan, W., Flunker, J. C., Westneat, S., \& Browning, S. R. (2017, setembro). Poor safety climate, long work hours, and musculoskeletal discomfort among Latino horse farm workers. Archives of environmental \& occupational health, 72(5), 264-27. 10.1080/19338244.2016.1216387.

Taylor-Gjevre, R. M., Trask, C., King, N., \& Koehncke, N. (2015, abril). Prevalence and occupational impact of arthritis in Saskatchewan farmers. Journal of agromedicine, 20(2), 205-216. 10.1080/1059924X.2015.1009666.

Thetkathuek, A., Meepradit, P., \& Sangiamsak, T. (2018, junho). A cross-sectional study of musculoskeletal symptoms and risk factors in Cambodian fruit farm workers in Eastern Region, Thailand. Safety and Health at Work, 9(2), 192-202. 10.1016/j.shaw.2017.06.009.

Tonelli, S., Culp, K., \& Donham, K. J. (2015, outubro). Prevalence of musculoskeletal symptoms and predictors of seeking healthcare among Iowa farmers. Journal of agricultural safety and health, 21(4), 229-239. 10.13031/jash.21.10825. 
Research, Society and Development, v. 10, n. 8, e19110817305, 2021

(CC BY 4.0) | ISSN 2525-3409 | DOI: http://dx.doi.org/10.33448/rsd-v10i8.17305

Tribble, A. G., Culp, K., \& Donham, K. J. (2016, outubro). Musculoskeletal pain, depression, and stress among Latino manual laborers in North Carolina. Archives of environmental \& occupational health, 71(6), 309-316. 10.1080/19338244.2015.1100104.

Ulbricht, L. (2003). Fatores de risco associados à incidência de DORT entre ordenhadores em Santa Catarina. Tese de Doutorado, Universidade Federal de Santa Catarina, Santa Catarina, Brasil. https://repositorio.ufsc.br/bitstream/handle/123456789/86444/191726.pdf?sequence.

Vasanth, D., Ramesh, N., Fathima, F. N., Fernandez, R., Jennifer, S., \& Joseph B. (2015, dezembro). Prevalence, pattern, and factors associated with workrelated musculoskeletal disorders among pluckers in a tea plantation in Tamil Nadu, India. Indian journal of occupational and environmental medicine, 19(3), 167-170. 10.4103/0019-5278.173992.

Ya'Acob, N. A., Abidin, E. Z., Rasdi, I., Rahman, A. A., \& Ismail, S. (2018, abril) Reducing work-related musculoskeletal symptoms through implementation of Kiken Yochi training intervention approach. Work, 60(1), 143-152. 10.3233/WOR-182711. 